\title{
EVALUATION OF DIMENSIONAL CHANGES OF MAXILLARY SINUS AND ALVEOLAR CREST AFTER PRESERVATION OF MAXILLARY EXTRACTION SOCKET WITH BIO-OSS AND PLATELET-RICH FIBRIN
}

\author{
Ahmed H. Hassan ${ }^{1 *}$, Mohammed A.Khalil ${ }^{2}$, Ahmed A.Al-Feky ${ }^{3}$
}

\begin{abstract}
Objectives: To evaluate reducing sinus pneumatization and alveolar crest resorption after extraction in posterior maxilla using bio-oss and PRF. Subjects and methods: Randomized, controlled, clinical study was done on 24 patients divided into 2 equal groups. In Group I (study), bio-oss was applied in posterior maxillary extraction socket then compressed PRF was adapted over the graft and sutured while in Group II (control), the socket was left without any grafting for spontaneous healing, CBCT was done to evaluate; maxillary sinus pneumatization and alveolar crest resorption. Three linear measurements was done on the CBCT at the middle of extraction site; from bone crest to sinus floor, from sinus floor to sinus roof, and sinus sagittal circumference. Sinus pneumatization and crest resorption were assessed immediately, 3 months, and 6 months post operatively. Results: The mean change in the distance from the bone crest to the sinus floor pre and post operatively was $0.32 \mathrm{~mm}$ in the study group and $1.26 \mathrm{~mm}$ in the control group. The mean change in the distance from the sinus floor to the sinus roof was $0.30 \mathrm{~mm}$ in the study group and $1.30 \mathrm{~mm}$ in the control group, and the mean change in the sinus sagittal circumference was $37.34 \mathrm{~mm}$ and $125.95 \mathrm{~mm}$, respectively. Conclusion: Application of bio-oss and PRF in posterior maxillary extraction socket seemed to reduce sinus pneumatization as well as alveolar crest resorption.
\end{abstract}

KEY WORDS: Sinus pneumatization, bone augmentation, dental implants, CBCT, platelet rich fibrin.

\section{INTRODUCTION}

The task of restoring the edentulous posterior maxilla with an implant-supported prosthesis can be complex. A major reason for this can be the lack of vertical bone remaining for stable implant placement after tooth loss. The lack of bone is thought to be the result of two processes: resorption of the maxillary alveolus ${ }^{(1,2)}$ and pneumatization of the maxillary sinus ${ }^{(3)}$.
Alveolar resorption has been shown by many to occur after the extraction of a tooth. This resorption results in both vertical and horizontal alveolar dimension loss intraorally ${ }^{(1,2)}$. Beyond intraoral resorption, teeth extracted in the posterior maxilla may also result in intra-antral resorption via inferior expansion of the maxillary sinus ${ }^{(3)}$.

Pneumatization of the maxillary sinus is a normal physiologic process that results in an increased

1. Masters Candidate, Dentist at Ministry of Health.

2. Professor, Department of Oral and Maxillofacial Surgery, Faculty of Dental Medicine, Al-Azhar university (Cairo, Boys).

3. Assistant Professor, Depatment of Oral and Maxillofacial Surgery, Faculty of Dental Medicine, Al-Azhar university (Cairo, Boys).

-Corresponding author: dr_a_hamdy4452002@yahoo.com 
volume of the sinuses during development ${ }^{(4)}$. Reasons why sinus pneumatization takes place are poorly understood. However, several factors including heredity, bone density, previous sinus surgery, and extraction of posterior maxillary teeth have been postulated as factors that influence the amount of sinus pneumatization ${ }^{(3)}$.

It has been reported that ridge preservation after tooth extraction minimizes the bone resorption of the socket walls therefore maintaining the anatomic shape of the alveolar ridge ${ }^{(5)}$. If ridge preservation acts by limiting the loss in hard tissue volume of the alveolus intraorally, it may also inhibit post-extraction sinus pneumatization. The purpose of this study was to evaluate maxillary sinus and alveolar crest dimensional changes after posterior maxillary tooth extraction, using bio-oss bone graft and platelet-rich fibrin for ridge preservation.

\section{SUBJECTS AND METHODS}

Twenty-four patients were selected from those attending outpatient clinic of the Department of Oral and Maxillofacial Surgery, Faculty of Dental Medicine, Boys, Cairo, Al-Azhar University, as a randomized, controlled clinical trial.

Inclusion criteria: Patients who underwent extraction of either the posterior maxillary teeth related to maxillary sinus, free of any sinus problems, and having free medical history.

Exclusion criteria: Cases of immediate implant placement, intra-operative sinus perforation, patients with osseo-metabolic disorder. e.g rheumatoid arthritis, and patients with systemically compromised situations like uncontrolled diabetes, liver and renal disorders, taking steroids or anti-cancer drugs.

\section{Patient grouping:}

The patients were divided randomly according to methods of treatment into two groups:
Control group (twelve patients): extraction one of maxillary posterior teeth without any grafting material.

Study group (twelve patients): extraction one of maxillary posterior teeth with application of bio-oss and platelet-rich fibrin for socket preservation.

\section{Preoperative assessment:}

All patients were prepared for surgery by the same protocol as the following:

1. Clinical evaluation: Extra oral and intra oral examinations were carried out; hard and soft tissue structures were evaluated. Extra oral examination involved the presence or absence of any pain, edema or TMJ disorders as sublaxation or dislocation.

2. Preoperative radiograph: CBCT was done preoperatively for each patient.

3. Oral hygiene measures (scaling and root planning).

\section{Preoperative procedures: PRF preparation}

The PRF was prepared as described by Choukroun et al. ${ }^{(6)}, 10 \mathrm{ml}$ of the patient's venous blood was drawn and placed in vacuum tube without anticoagulant, and was immediately centrifuged as a single spin at $3000 \mathrm{rpm}$ for 10 minutes at room temperature.

After centrifugation, the PRF clot was removed from the tube using sterile tweezer. Then the PRF clot was separated from the attached RBC base using scissors, compressed to be used as a membrane.

\section{Surgical procedures:}

Local anaesthetic (MepecaineHcl 2\% with vasoconstrictor levonordefrine 1:20000 Alexandria company) was injected with buccal and palatal infiltration for anaesthetizing of the extraction site.

The standard surgical protocol included atraumatic extraction, socket debridement and primary closure of the soft tissues. Patients were asked to rinse with chlorhexidine mouthwash (chlorhexi- 
dineglyconate $0.2 \%$ Adco company, Egypt) for 30 seconds. Under local anesthesia, minimally a traumatic extraction of the tooth was performed, without performing ostectomy. A careful socket debridement was performed with manual instruments from the bottom of the socket up to the gingival margin.

In control group, the extraction sockets were left without any preservation procedure just for spontaneous healing. In study group, Extraction of a maxillary posterior tooth was done with application of bio-oss (bio-oss spongious granules, Geistlich pharma AG, Bahnhofstrasse 40, 6110 Wolhusen, Switzerland) and covered by platelet-rich fibrin for socket preservation. The PRF membrane was seated over the graft material and sutured with soft tissue margins to act as a barrier membrane and assure proper healing.

\section{Post-Operative Instructions:}

Patients were instructed to bite down gently but firmly on the gauze packs that have been placed over the extraction areas, making sure they remain in place and not to change them for the first hour unless the bleeding was not controlled, avoid rinsing vigorously and hot drinks and stick to soft diet.

\section{Medications:}

Postoperatively, all patients received analgesics (nonsteroidal anti-inflammatory drugs for 3 days) and antibiotics for 1 week (amoxicillin plus clavulanic acid) when needed. Sutures were removed after 7 days and patients entered in a follow-up protocol with periodic professional dental hygiene recalls.

\section{Post-operative assessment:}

Clinical evaluation was the assessment of the extraction socket healing. All the radiographic measurements were performed by one examiner, following several training sessions which included identification of landmarks, matching of radiographs and measurements.

CBCT (Vatech, Korea, Scientific zone Egypt) radiograph was taken immediately after operation, and at interval three months and then six months after extraction. Matching of radiographs were performed by superimposition (Planmeca Romexis 5.3.4.39 software) in region of interest using fixed reference structures, such as teeth and dental implants adjacent to the region of interest (Fig.1).

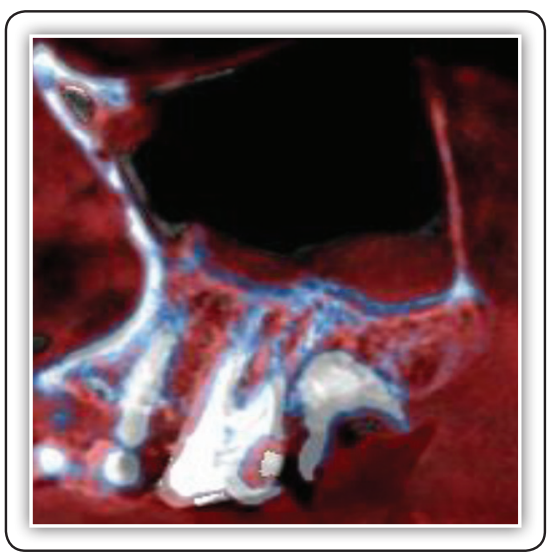

FIG (1) Superimposition of two CBCTs preoperative (blue) and after follow up period (red)

\section{The following linear measurements were pre- formed (Fig.2-4):}

- Distance between the bone crest (BC) in the middle of the extraction site and the sinus floor.

- Distance between the sinus floor in the middle of the extraction site and the sinus roof.

- Maxillary sinus sagittal circumference-Maxillary sinus wall circumference measured on the CBCT.

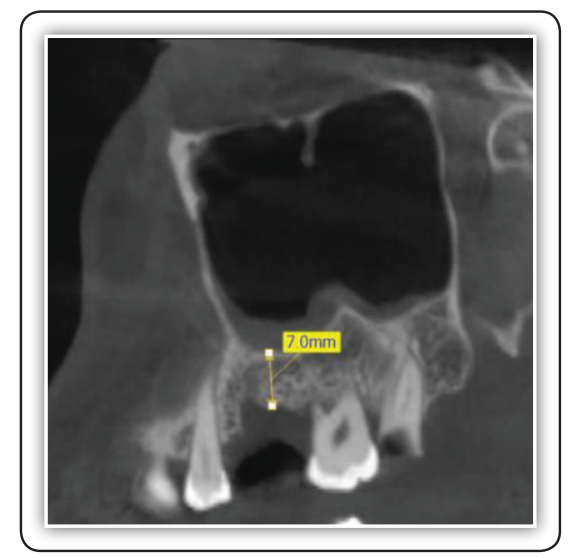

FIG (2) Sagittal view CBCT showing bone crest to sinus floor measurement 


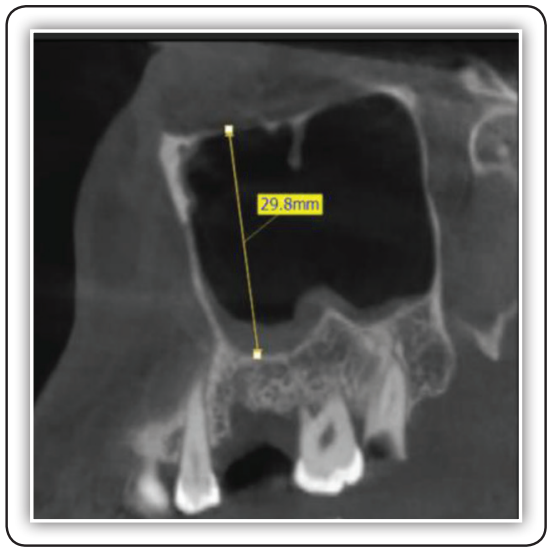

FIG (3) Sagittal view CBCT showing sinus Floor to sinus roof measurement

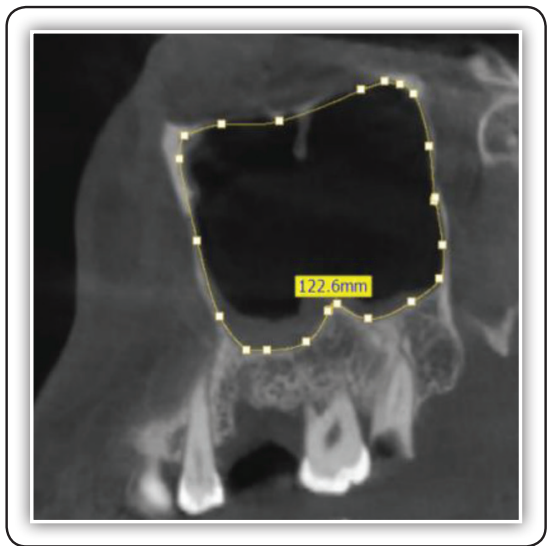

FIG (4) Sagittal view CBCT showing sinus wall circumference measurement

\section{Analysis of the data}

Data were fed to the computer and analyzed using IBM SPSS software package version 20.0. (Armonk, NY: IBM Corp), qualitative data were described using number and percent. The Kolmogorov-Smirnov test was used to verify the normality of distribution Quantitative data were described using range (minimum and maximum), mean, standard deviation and median. Significance of the obtained results was judged at the $5 \%$ level.

\section{RESULTS}

\section{Demographic data:}

Twelve patients ranged in age between 41.0 46.0 years with a mean age of $43.83 \pm 1.83$ years for study group and twelve patients ranged in age between 33.0 - 36.0 years with a mean age $34.50 \pm$ 1.05 years for control group. There was statistically non-significant difference between the two groups regarding to the mean of age.

\section{BC- floor (mm):}

Both group showed a statistically a significant decrease in mean BC- floor $(\mathrm{mm})$ measurements at 3 and 6 months. Immediate, 3 months, and 6 months: there was a statistically non-significant difference in mean BC- floor ( $\mathrm{mm}$ ) in the two groups (tab.1).

TABLE (1) Comparison between the two studied groups according to $\mathrm{BC}$ - floor (mm)

\begin{tabular}{|l|c|c|c|c|}
\hline & \multicolumn{1}{|c|}{$\begin{array}{c}\text { Study } \\
(\mathbf{n}=6)\end{array}$} & $\begin{array}{c}\text { Control } \\
(\mathbf{n}=\mathbf{6})\end{array}$ & $\mathbf{t}$ & $\mathbf{p}$ \\
\hline BC- floor (mm) \\
\hline Immediate & $9.36 \pm 1.54$ & $8.95 \pm 1.51$ & 0.465 & 0.652 \\
\hline 3 months & $8.62 \pm 1.44$ & $7.60 \pm 1.47$ & 1.220 & 0.251 \\
\hline 6 months & $8.42 \pm 1.39$ & $7.16 \pm 1.77$ & 1.367 & 0.201 \\
\hline
\end{tabular}

$\mathrm{t}$ : Student t-test

$\mathrm{p}$ : $\mathrm{p}$ value for comparing between the studied groups

\section{Floor-roof (mm):}

Both group showed a statistically significant increase in mean floor-roof $(\mathrm{mm})$ measurements at 3 and 6 months. Immediate, 3 months, and 6 months: there was a statistically non-significant difference in mean floor-roof (mm) in the two groups (tab.2).

TABLE (2): Comparison between the two studied groups according to floor-roof $(\mathrm{mm})$

\begin{tabular}{|l|c|c|c|c|}
\hline & \multicolumn{1}{|c|}{$\begin{array}{c}\text { Study } \\
(\mathbf{n = 6})\end{array}$} & $\begin{array}{c}\text { Control } \\
(\mathbf{n = 6})\end{array}$ & $\mathbf{t}$ & $\mathbf{p}$ \\
\hline \multicolumn{5}{|l|}{ Floor-roof $(\mathbf{m m})$} \\
\hline Immediate & $28.10 \pm 1.06$ & $27.90 \pm 1.79$ & 2.349 & 0.141 \\
\hline 3 months & $28.83 \pm 1.22$ & $29.41 \pm 2.14$ & 1.412 & 0.188 \\
\hline 6 months & $28.98 \pm 1.20$ & $29.92 \pm 2.48$ & 0.943 & 0.368 \\
\hline
\end{tabular}

t: Student t-test

$\mathrm{p}$ : $\mathrm{p}$ value for comparing between the studied groups

*: Statistically significant at $\mathrm{p} \leq 0.05$ 


\section{Sagittal circumference (mm):}

Both group showed a statistically significant increase in mean sagittal circumference $(\mathrm{mm})$ measurements at 3 and 6 months. Immediate; there was a statistically non-significant difference in mean sagittal circumference $(\mathrm{mm})$ in the two groups. At 3 months; there was a statistically significant difference in mean sagittal circumference $(\mathrm{mm})$ in the two groups. Study group showed a lower sagittal circumference $(\mathrm{mm})$ than control group. At 6 months; there was a statistically significant difference in mean sagittal circumference $(\mathrm{mm})$ in the two groups. Study group showed a lower sagittal circumference $(\mathrm{mm})$ than control group (tab.3).

TABLE (3): Comparison between the two studied groups according to sagittal circumference $(\mathrm{mm})$

\begin{tabular}{|l|c|c|c|c|}
\hline & \multicolumn{1}{|c|}{$\begin{array}{c}\text { Study } \\
(\mathbf{n = 6})\end{array}$} & $\begin{array}{c}\text { Control } \\
(\mathbf{n = 6})\end{array}$ & $\mathbf{t}$ & $\mathbf{p}$ \\
\hline \multicolumn{5}{|l|}{ Sagittal circumference (mm) } \\
\hline Immediate & $84.33 \pm 2.66$ & $85.17 \pm 2.04$ & 2.071 & 0.065 \\
\hline 3 months & $85.50 \pm 2.81$ & $89.0 \pm 1.90$ & $2.528^{*}$ & $0.033^{*}$ \\
\hline 6 months & $86.67 \pm 3.08$ & $91.67 \pm 1.86$ & $3.406^{*}$ & $0.009^{*}$ \\
\hline
\end{tabular}

t: Student t-test

$\mathrm{p}$ : $\mathrm{p}$ value for comparing between the studied groups

*: Statistically significant at $\mathrm{p} \leq 0.05$

\section{Change of BC- floor, floor-roof, and sagittal circumference:}

Regarding change of $\mathrm{BC}$ - floor (mm) at 3 and 6 months: there was a statistically significant difference in mean BC- floor $(\mathrm{mm})$ in the two groups. Study group showed a less change of BC- floor $(\mathrm{mm})$ than control group. Regarding change of Floor-roof ( $\mathrm{mm})$ at 3 and 6 months: there was a statistically significant difference in mean Floor-roof $(\mathrm{mm})$ in the two groups. Study group showed a less change of Floor-roof (mm) than control group. Regarding change of Sagittal circumference $(\mathrm{mm})$ at 3 and 6 months: there was a statistically significant difference in mean change of Sagittal circumference $(\mathrm{mm})$ in the two groups. Study group showed a less change of Sagittal circumference ( $\mathrm{mm}$ ) than control group (tab.4).

TABLE (4): Comparison between the two studied groups according to change of $\mathrm{BC}$ - floor, floor-roof and sagittal circumference

\begin{tabular}{|c|c|c|c|c|}
\hline $\begin{array}{c}\text { Change from } \\
\text { Immediate to }\end{array}$ & $\begin{array}{c}\text { Study } \\
(\mathbf{n}=\mathbf{6})\end{array}$ & $\begin{array}{c}\text { Control } \\
(\mathbf{n}=6)\end{array}$ & $\mathbf{U}$ & $\mathbf{p}$ \\
\hline BC- floor (mm) \\
\hline 3 months & $0.74 \pm 0.32$ & $1.36 \pm 0.11$ & $0.000^{*}$ & $0.002^{*}$ \\
\hline 6 months & $0.94 \pm 0.41$ & $1.79 \pm 0.41$ & $4.000^{*}$ & $0.026^{*}$ \\
\hline Floor-roof (mm) \\
\hline 3 months & $0.73 \pm 0.49$ & $1.50 \pm 0.47$ & $2.000^{*}$ & $0.009^{*}$ \\
\hline 6 months & $0.88 \pm 0.58$ & $2.02 \pm 0.71$ & $4.000^{*}$ & $0.026^{*}$ \\
\hline Sagittal circumference (mm) \\
\hline 3 months & $1.17 \pm 0.41$ & $3.83 \pm 0.41$ & $0.000^{*}$ & $0.002^{*}$ \\
\hline 6 months & $2.33 \pm 0.52$ & $6.50 \pm 0.55$ & $0.000^{*}$ & $0.002^{*}$ \\
\hline
\end{tabular}

U: Mann Whitney test

$\mathrm{p}$ : $\mathrm{p}$ value for comparing between the studied groups

*: Statistically significant at $\mathrm{p} \leq 0.0$

\section{DISCUSSION}

The values for sinus pneumatization Sagittal circumference $(\mathrm{mm})$ and Floor-roof $(\mathrm{mm})$ observed in the nongrafted group $(6.50 \pm 0.55,2.02 \pm 0.71$ respectively) agree with a previous study by Sharan and Madjar ${ }^{(3)}$ showing an increase of sinus dimension for the same site pre and post extraction without crestal bone preservation. Levi et al., (7) compared dimensional changes in the alveolar ridge and corresponding maxillary sinus following tooth extraction, with or without ridge preservation. The mean change in the distance from the sinus floor to the sinus roof pre and post operatively was 0.30 $\mathrm{mm}$ in the study group and $1.30 \mathrm{~mm}$ in the control group. The mean change in the distance from the bone crest to the sinus floor was $0.32 \mathrm{~mm}$ in the study group and $1.26 \mathrm{~mm}$ in the control group, and the mean change in the sinus sagittal circumference was $37.34 \mathrm{~mm}$ and $125.95 \mathrm{~mm}$, respectively. They concluded that, ridge preservation using xenograft 
might reduce sinus pneumatization along with minimizing crestal bone resorption.

The changes observed in the crestal bone height (BC-Floor), should be interpreted considering previous studies ${ }^{(8,9)}$. A systematic review by Van der Weijden and colleagues, ${ }^{(1)}$ reported a mean crestal height change post extraction without socket preservation. Crestal bone preservation procedures were found to significantly reduce the vertical and horizontal bone dimensional changes. Studies which compared extraction sites with and without alveolar preservation using xenograft, showed a linear modification in ridge height generally higher for the untreated sites with clinical changes ranging from 21.12 to $21.67 \mathrm{~mm}^{(10,11)}$.

The preservation of the crestal bone seemed to significantly influence the sinus sagittal circumference changes: $91.67 \pm 1.86$ and $86.67 \pm 3.08$ for the nongrafted and grafted sites, respectively. In accordance with Levi et al., ${ }^{(7)}$, The preservation of the crestal bone seemed to significantly influence the sinus sagittal circumference changes for the nongrafted and grafted sites.

The resorption of the alveolus after tooth extraction has been reported ${ }^{(1)}$. Intraorally, this reduction translates to an average horizontal and vertical bone loss of $3.74 \mathrm{~mm}$ and $1.67 \mathrm{~mm}$, respectively ${ }^{(1)}$. Intra-antrally, the extraction of the tooth will also result in the loss of alveolar bone seen via the inferior expansion of the maxillary sinus ${ }^{(3)}$. Results from another study showed a similar trend of sinus expansion through the volumetric increase in 0.50 cc recorded after extraction of posterior maxillary teeth without ridge preservation.

It could be hypothesized that a loss in functional stimulation from the tooth may result in the loss of mechano-transductional signals at the periodontal ligament junction with the bundle bone. The resulting change in local cell signaling could be responsible for the differentiation of local progenitor cells into osteoclasts which resorbed the internal cortical bones of the alveolus. The hypothesis might also explain the additional bone loss seen in the coronal third of the buccal plate. The coronal third of buccal plate is made almost entirely of bundle bone and therefore, is very thin ${ }^{(12)}$. If we apply the concepts of Wolff's law to the thin bundle bone in the coronal third of the buccal plate just after an extraction, the resulting loss in functional stimulation may produce a significant amount of bone remodeling as reported by Araujo $2005^{(12)}$ and $2008^{(13)}$ and $2009^{(14)}$.

By taking this one step further, the same concept might also be applicable to the post-extraction changes seen in the floor of the maxillary sinus. The cortical bone of the buccal plate is similar in structure to inferior border of the maxillary sinus in cases where root apices of maxillary posterior teeth are in close proximity to the sinus floor ${ }^{(15)}$. Therefore, if the coronal third of the buccal plate, composed almost entirely of bundle bone, has been shown to undergo dramatic dimensional changes after an extraction, then a thin component of apical bone between of the root apex and floor of the sinus may do the same. Evidence to support this hypothesis could be observed radiographically after extraction of posterior maxillary teeth with a superiorly curving sinus floor ${ }^{(3)}$.

Data presented in this study appear to support the notion that significant post-extraction sinus pneumatization might be reduced via ridge preservation. Although, further studies are needed to state these information with less limitations like taking in consideration the patient's bone quality, age, number and position of extracted teeth and type of graft material.

\section{CONCLUSIONS}

According to results of this study, it can be concluded that:

- Maxillary sinus pneumatization may be reduced when preserving the maxillary posterior extraction socket. 
- Ridge preservation using bio-oss bone graft with PRF membrane seemed to reduce the normally occurring sinus pneumatization after extraction of maxillary posterior teeth.

- Using bio-oss and PRF seemed to reduce crestal bone loss after dental extraction.

- Further studies are required to substantiate these findings and appreciate its magnitude.

\section{REFERENCES}

1. van der Weijden, Dell'Acqua F, Slot D. Alveolar bone dimensional changes of post-extraction sockets in humans: A systematic review. J Clin Periodontol. 2009;36:10481058.

2. Tan W, Wong T, Wong M, Lang N. A systematic review of post-extractional alveolar hard and soft tissue dimensional changes in humans. Clin Oral Impl Res. 2012;23:1-21.

3. Sharan A, Madjar D. Maxillary sinus pneumatization following extractions: A radiographic study. Int J Oral Maxillofac Implants. 2008;23:48-56.

4. Peterson L. Contemporary Oral and Maxillofacial Surgery, 2nd Edition. BC Decker, 2004.

5. Iasella J, Greenwell H, Miller R, Hill M, Drisko C, Bohra A, Scheetz J. Ridge preservation with freeze-dried bone allograft and a collagen membrane compared to extraction alone for implant site development: A clinical and histologic study in humans. J Periodontol. 2003;74:990-999.

6. Boora P, Rathee M, Bhoria M. Effect of platelet rich fibrin (PRF) on peri-implant soft tissue and crestal bone in onestage implant placement: a randomized controlled trial. J Clin Diagn Res. 2015;9(4):18-21.

7. Levi I, Halperin-Sternfeld M, Horwitz J, Zigdon-Giladi H, Machtei E. Dimensional changes of the maxillary sinus following tooth extraction in the posterior maxilla with and without socket preservation. Clin Implant Dent Relat Res. 2017;19(5):952-958.

8. Schropp L, Wenzel A, Kostopoulos L, Karring T. Bone healing and soft tissue contour changes following singletooth extraction: a clinical and radiographic 12-month prospective study. Int J Periodontics Restorative Dentistry. 2003;8:313-324.

9. Pietrokovski J, Massler M. Alveolar ridge resorption following tooth extraction. J Prosthet Dent. 1967;17(1): 21-27.

10. Kotsakis G, Salama M, Chrepa V, Hinrichs J, Gaillard P. A randomized, blinded, controlled clinical study of particulate anorganic bovine bone mineral and calcium phosphosilicate putty bone substitutes for socket preservation. Int J Oral Maxillofac Implants. 2014;29(1):141-151.

11. Cardaropoli D, Tamagnone L, Roffredo A, Gaveglio L. Relationship between the buccal bone plate thickness and the healing of postextraction sockets with/without ridge preservation. Int J Periodont Restorative Dentistry. 2014;2:211-217.

12. Araujo M, Lindhe J. Dimensional ridge alterations following tooth extraction. An experimental study in the dog. J Clin Periodontol. 2005;32:212-218.

13. Araujo M, Linder E, Wennstrom J, Lindhe J. The influence of bio-oss collagen on healing of an extraction socket: an experimental study in the dog. Int J Periodontics and Restorative Dentistry. 2008;28:123-135.

14. Araujo M, Lindhe J. Ridge preservation with the use of bio-oss collagen: a 6-month study in the dog. Clin Oral Impl Res. 2009;20:433-440.

15. Kwok H, Park D, Yoon H, Kang M, Koh K, Kim H. Topographical anatomy of the inferior wall of the maxillary sinus in Koreans. Int J Oral Maxillofac Surg. 2004;33: 382-388. 